\title{
Effects of Chelated Iron on Roots under Different Mulching Materials on Fruit Quality of Huangguogan
}

\author{
Zhaofang Chen ${ }^{1}$, Liting Wen ${ }^{1}$, Liancong Yang ${ }^{3}$, Youting Yang ${ }^{1}$, Liping Tan ${ }^{1}$, Xiaojia Wang ${ }^{1}$, Shengjia Huang $^{1}$, Xia Qiu ${ }^{1}$, \\ Bo Xiong ${ }^{1}$, Honghong Deng ${ }^{1}$, Ling Liao ${ }^{1}$, Guochao Sun ${ }^{2}$, and Zhihui Wang ${ }^{2}$ * \\ ${ }^{1}$ College of Horticulture, Sichuan Agricultural University, 611130 Chengdu, Sichuan, China \\ ${ }^{2}$ Institute of Pomology \& Olericulture, Sichuan Agricultural University, 611130 Chengdu, Sichuan, China \\ ${ }^{3}$ College of Environmental, Sichuan Agricultural University, 611130 Chengdu, Sichuan, China
}

\begin{abstract}
In this experiment, Huangguogan in Shimian County was selected as the experimental material, and the effects of different treatments on the fruit quality of Huangguogan were studied by mulching treatments with black film, straw, horticultural cloth and river sand. The results of this study showed that the application of chelated iron to the roots under different mulching materials could significantly improve the fruit quality, and the application of chelated iron to the roots under different mulching materials had different effects on fruit quality. The river sand mulching treatment had the highest single fruit weight, vertical and horizontal diameters, while CK had the lowest one. The four mulching treatments all increased the contents of total soluble solids, soluble sugar and sucrose. The river sand mulching treatment had the highest contents, which were $13.96 \%, 13.09$ and $6.93 \mathrm{~g} \cdot 100 \mathrm{~mL}^{-1}$, respectively. There were significant differences in the titratable acid, vitamins $\mathrm{C}$ and sugar-acid ratio between the different mulching treatments, and the river sand mulching treatment had the highest effect. In general, the river sand mulching treatment had the best effect on promoting fruit quality, and plastic film mulching treatment had the worst effect.
\end{abstract}

\section{Introduction}

Citrus is a commercially important genus of the family Rutaceae and widely cultivated fruit crop in the world [1]. Natural and cultivated origin hybrids include commercially important fruit such as the oranges, grapefruit, lemons, some limes, and some tangerines. Huangguogan (Citrus reticulata $\times$ Citrus sinensis) is hybrid citrus cultivars, which have been identified as a new cultivated variety in China. In recent years, the plant area of Huangguogan has been expanded rapidly in the southwest of China [2]. Huangguogan was a hybrid variety of Rutaceae Citrus family. It originated from Shimian County, Ya'an City, Sichuan Province, and was a local late ripening characteristic fruit. It matures from March to May of the following year. The fruit has excellent characteristics such as extremely high yield, seedless, sweet and sour, and strong adaptability.

Plastic film mulch planting technology is a practical technology widely used in agricultural production. Black mulching for water-controlling and sugar-increasing cultivation of orange orchards was first applied in Japan. At present, there were already a certain area of plasticmulching water-controlling cultivation in the main citrus production area, but there were still a series of problems in production [3]. Film mulching, grass mulching and grass growing were common ground management measures for orchards to reduce artificial input. In recent years, mulching materials such as green grass, straw, and plastic film have been widely used in the research of orchard ground water conservation and mulching technology. Among them, plastic film mulching has been widely used on crops such as apples, pears, navel oranges, and sweet grapefruits [4]. Plastic film mulching can stabilize soil temperature, improve soil microenvironment and physical and chemical properties and orchard microclimate environment, at the same time increase soil enzyme activity and fertility levels, fruit yield and quality, and reduce field water evaporation. The black film has low light transmittance and less radiant heat. Mulching the black film during the fruit tree growing season can effectively reduce the ground temperature, maintain soil moisture for a longer time, improve water use efficiency and leaf photosynthetic capacity, and inhibit weed growth [5]. Plastic film mulch can also slow down the loss of water, soil and nutrients, while increase the soil iron, zinc, boron and other elements, and the loss of nutrients in the soil decreases with the increase in mulching. The plastic film mulching of the orchard is beneficial to regulate the growth of the tree body, improve the distribution of roots in the soil, enhance the photosynthetic rate of the fruit tree, improve fruit quality and increase fruit yield.

Plastic film mulch is an effective measure to reduce soil water evaporation and alleviate sudden changes in ground temperature, and different plastic film mulch materials have different effects on soil conditions. In order to study the effect of different materials on the fruit

\footnotetext{
* Corresponding author: Zhihui Wang@ wangzhihui318@126.com
} 
quality, this study focused on using Huangguogan as the experimental sample to carry out cultivation experiments with different mulching materials, excepting to provide a scientific reference for the selection of the best mulching material in the production of Huangguogan.

\section{Materials and Methods}

\subsection{Experimental materials}

Eight-years Huangguogan, planted in the Huangguogan planting base in Shimian County, were selected in this study. There were nine Huangguogan trees for each of the four treatments. All trees were robust, moderately managed, free of pests and diseases, and spaced $3 \mathrm{~m} \times 4$ $\mathrm{m}$ apart. Three samples were randomly harvested from each treatment as three biological repeats. The experimental fertilizer was high-efficiency EDDHA chelated iron which was $6.0 \%$ and was suitable for all kinds of fruit trees, and it was produced by Sichuan Jielifu Biological Technology Co., Ltd.

\subsection{Experimental design}

This experiment focused on a single-factor four level experiment. The mulching materials were mulch, straw, horticultural cloth and river sand, and they were marked as $\mathrm{A}, \mathrm{B}, \mathrm{C}$, and $\mathrm{D}$, respectively. The blank without mulching was used as a control (CK). With a single plant as the plot, a total of 15 test materials were selected. The test treatment was shown in Table 1.

After the fruits were picked, the rhizosphere fertilization was carried out from the end of April to the beginning of May. According to the results of the preliminary experiment, $30 \mathrm{~g}$ of EDDHA-Fe was applied to each Huangguogan fruit tree. The application method was as follows: EDDHA was first dissolved in water, and it was applied into a shallow trench dug about $10 \mathrm{~cm}$ under the Huangguogan drip line. The left and right sides of the tree trunk were mulched with black mulch, straw mulch, horticultural cloth mulch and river sand mulch in a row at a distance of $10 \mathrm{~cm}$ from the tree trunk, and the other management measures of the mulched orchard were as usual carried out.

Table 1. Treatment of rhizosphere fertilization with different mulching materials.

\begin{tabular}{|c|c|}
\hline Treatment & Experimental method \\
\hline A & black mulch \\
\hline B & straw mulch \\
\hline C & horticultural cloth mulch \\
\hline D & river sand mulch \\
\hline CK & no coverage \\
\hline
\end{tabular}

\subsection{Experimental methods}

\subsubsection{Determination of soil $\mathrm{pH}$}

After the fertilization treatment, the determination was carried out in mid-May, mid-September, and midJanuary of the following year, and they were marked as $\mathrm{T} 1, \mathrm{~T} 2$ and $\mathrm{T} 3$, respectively. After treatment, soil $\mathrm{pH}$ was measured in mid-May, mid-September, and midJanuary of the following year. The soil $\mathrm{pH}$ was measured by using a soil $\mathrm{pH}$ meter in four directions around the fertilization circle of each tree.

\subsubsection{Determination of fruit appearance quality}

The fruit quality was determined after the fruit was mature. Four samples were randomly picked from the four directions of each tree in the south, east, north and west. The single fruit weight was measured by $1 \%$ electronic balance and expressed as g. The vertical and the horizontal diameter $(\mathrm{mm})$ were measured using an electronic digital slide gauge, there the fruit shape index (FSI) was calculated by the vertical diameter / horizontal diameter.

\subsubsection{Determination of fruit nutritional quality}

The total solid soluble (TSS) content of the juice was determined using TD-45 digital refractometer. The soluble sugar (Sugar) was determined by of anthronesulfuric acid method [6], with the results expressed as percentage (\%). The titratable acidity (TA) was determined by potentiometric titration of the orange juice, with the results expressed as percentage (\%) of citric acid equivalent [6]. Acid-sugar ratio was calculated as the ratio as relationship between Sugar and TA, and solid-acid ratio was calculated as the ratio as relationship between TSS and TA. The content of vitamin C (Vc) was determined by the 2,6-dichlorophenolindophenol sodium salt titration method [6].

\subsection{Statistical analysis}

The data were prepared with Microsoft Excel. Statistical analysis was performed using SPSS software (ver. 23.0) at $P<0.05$. The significance of differences among the data was determined with Student-Newman-Keuls' (SNK) multiple-range test.

\section{RESULTS}

\subsection{Determination of $\mathrm{pH}$ in soil}

Shallow application of different mulching materials near the roots of Huangguogan tree can significantly decrease the soil $\mathrm{pH}$ (Table 2), but there was no significant difference between different mulching treatments. The soil $\mathrm{pH}$ increased slightly in September, and the soil $\mathrm{pH}$ decreased again in January of the following year. 
Table 2. The pH in soil after applying chelated iron to roots under different mulching materials.

\begin{tabular}{|c|c|c|c|}
\hline \multirow{2}{*}{ Treatment } & \multicolumn{3}{|c|}{$\mathrm{pH}$} \\
\cline { 2 - 4 } & $\mathrm{T} 1$ & $\mathrm{~T} 2$ & $\mathrm{~T} 3$ \\
\hline $\mathrm{A}$ & $6.50 \pm 0.058 \mathrm{~b}$ & $6.60 \pm 0.058 \mathrm{~b}$ & $6.57 \pm 0.033 \mathrm{~b}$ \\
\hline B & $6.60 \pm 0.058 \mathrm{~b}$ & $6.67 \pm 0.033 \mathrm{~b}$ & $6.47 \pm 0.033 \mathrm{~b}$ \\
\hline C & $6.57 \pm 0.088 \mathrm{~b}$ & $6.70 \pm 0.058 \mathrm{~b}$ & $6.47 \pm 0.033 \mathrm{~b}$ \\
\hline D & $6.57 \pm 0.033 \mathrm{~b}$ & $6.73 \pm 0.033 \mathrm{~b}$ & $6.57 \pm 0.033 \mathrm{~b}$ \\
\hline CK & $6.83 \pm 0.033 \mathrm{a}$ & $6.93 \pm 0.033 \mathrm{a}$ & $6.80 \pm 0.058 \mathrm{a}$ \\
\hline
\end{tabular}

Note: Different lowercase letters within columns indicate significant differences $(P<0.05)$ between different treatments. The same below.

\subsection{Determination of fruit appearance quality}

Treatments with different mulching materials can significantly increase the appearance quality of Huangguogan fruit (Table 3), and there were significant differences between different mulching treatments. The single fruit weight, vertical diameter and horizontal diameter of CK were the lowest, with values of $125.62 \mathrm{~g}$, $53.40 \mathrm{~mm}$, and $60.51 \mathrm{~mm}$, respectively, which were significantly lower than the other treatments. After the treatment of river sand mulching, the single fruit weight, horizontal diameter and vertical diameter of Huangguogan fruit were the highest, and the increase was the largest, followed by $146.64 \mathrm{~g}, 66.10 \mathrm{~mm}$, and $77.26 \mathrm{~mm}$, respectively. Compared with $\mathrm{CK}$, the black mulching treatment had the least increase, but it was significantly higher than $\mathrm{CK}$, and significantly lower than the other treatments. The single fruit weight, vertical diameter and horizontal diameter of the black mulching treatment were $128.11 \mathrm{~g}, 54.70 \mathrm{~mm}$ and 66.24 $\mathrm{mm}$, respectively. Black mulching and straw mulching treatments had the highest fruit shape index, which were 1.21 and 1.20 , respectively, and there was no significant difference between them. Followed by horticultural cloth mulching and river sand mulching, with fruit shape indexes of 1.16 and 1.17, respectively, and there was no significant difference between them. While CK had the lowest fruit shape index, which was 1.13, and it was significantly lower than the other treatments.

Table 3. Appearance quality after applying chelated iron to roots under different mulching materials.

\begin{tabular}{|c|c|c|c|c|}
\hline $\begin{array}{c}\text { Treatme } \\
\mathrm{nt}\end{array}$ & $\begin{array}{c}\text { Single fruit } \\
\text { weight } \\
/ \mathrm{g}\end{array}$ & $\begin{array}{c}\text { Vertical } \\
\text { diameter } \\
/ \mathrm{mm}\end{array}$ & $\begin{array}{c}\text { Horizontal } \\
\text { diameter } \\
/ \mathrm{mm}\end{array}$ & $\begin{array}{c}\text { Fruit } \\
\text { shape } \\
\text { index }\end{array}$ \\
\hline $\mathrm{A}$ & $\begin{array}{c}128.11 \pm 0.83 \\
8 \mathrm{~d}\end{array}$ & $\begin{array}{c}54.70 \pm 0.18 \\
0 \mathrm{~d}\end{array}$ & $\begin{array}{c}66.24 \pm 0.44 \\
2 \mathrm{~d}\end{array}$ & $\begin{array}{c}1.21 \pm 0.00 \\
6 \mathrm{a}\end{array}$ \\
\hline \multirow{2}{*}{$\mathrm{B}$} & $\begin{array}{c}135.56 \pm 0.72 \\
5 \mathrm{c}\end{array}$ & $\begin{array}{c}57.06 \pm 0.19 \\
2 \mathrm{c}\end{array}$ & $\begin{array}{c}68.47 \pm 0.51 \\
2 \mathrm{c}\end{array}$ & $\begin{array}{c}1.20 \pm 0.00 \\
5 \mathrm{a}\end{array}$ \\
\hline $\mathrm{C}$ & $\begin{array}{c}141.15 \pm 0.76 \\
9 \mathrm{~b}\end{array}$ & $\begin{array}{c}62.36 \pm 0.16 \\
0 \mathrm{~b}\end{array}$ & $\begin{array}{c}72.21 \pm 0.43 \\
8 \mathrm{~b}\end{array}$ & $\begin{array}{c}1.16 \pm 0.00 \\
9 \mathrm{~b}\end{array}$ \\
\hline $\mathrm{D}$ & $146.64 \pm 1.13$ & $66.10 \pm 0.39$ & $77.26 \pm 0.47$ & $1.17 \pm 0.00$ \\
& $5 \mathrm{a}$ & $8 \mathrm{a}$ & $8 \mathrm{a}$ & $7 \mathrm{~b}$ \\
\hline $\mathrm{CK}$ & $125.62 \pm 1.65$ & $53.40 \pm 0.29$ & $60.51 \pm 0.33$ & $1.13 \pm 0.00$ \\
& $1 \mathrm{~d}$ & $9 \mathrm{e}$ & $1 \mathrm{e}$ & $3 \mathrm{c}$ \\
\hline
\end{tabular}

\subsection{Determination of fruit nutritional quality}

The nutritional quality of Huangguogan fruit treated with different mulching materials has been significantly improved (Table 4). The river sand mulching treatment had the highest contents of sucrose, Sugar, vitamin C, TSS, and titratable acid. The river sand mulching treatment showed the highest sucrose content at 6.93 $\mathrm{g} \cdot 100 \mathrm{~mL}^{-1}$, which was significantly higher than the other treatments, followed by straw mulching treatment $\left(5.08 \mathrm{~g} \cdot 100 \mathrm{~mL}^{-1}\right)$. CK had the lowest sucrose content (3.81 g $\left.100 \mathrm{~mL}^{-1}\right)$, which was significantly lower than the other treatments. The Sugar content under the river sand mulching treatment was also the highest, with a content of $13.09 \mathrm{~g} \cdot 100 \mathrm{~mL}^{-1}$, which was significantly higher than the other treatments and CK, followed by the straw mulching and horticultural cloth mulching treatments. The lowest Sugar content was in CK at 7.97 $\mathrm{g} \cdot 100 \mathrm{~mL}^{-1}$, which was lower than the other treatments. The content of vitamin $\mathrm{C}$ was also the highest under the river sand mulching treatment at $13.11 \mathrm{mg} \cdot 100 \mathrm{~mL}^{-1}$, which was significantly higher than the other treatments, followed by the horticultural cloth mulching (11.88 $\mathrm{mg} \cdot 100 \mathrm{~mL}^{-1}$ ). The vitamin $\mathrm{C}$ content of CK was the lowest $\left(8.98 \mathrm{mg} \cdot 100 \mathrm{~mL}^{-1}\right)$, which was significantly lower than the other treatments. Under the treatment of different mulching materials, the contents of sucrose, Sugar and vitamin $\mathrm{C}$ of Huangguogan showed different levels of significant difference.

The TSS under the river sand mulching treatment $(13.96 \%)$ was significantly higher than the other treatments. Secondly, the content of TSS mulched by straw and horticultural cloth was higher, and there was no significant difference between them, and the TSS contents of straw and horticultural cloth mulching were $12.43 \%$ and $12.39 \%$, respectively. The TSS content of CK was the lowest at $9.58 \%$, which was significantly lower than the other mulching treatments. There were significant differences in the titratable acid content between different mulching treatments. The titratable acid content of river sand mulching was the highest $(0.68$ $\left.\mathrm{g} \cdot 100 \mathrm{~mL}^{-1}\right)$, followed by straw mulching $(0.55 \mathrm{~g} \cdot 100$ $\mathrm{mL}^{-1}$ ). There was no significant difference between the horticultural cloth mulching and black mulching treatments, and CK had the lowest content, which was $0.47 \mathrm{~g} \cdot 100 \mathrm{~mL}^{-1}$. The horticultural cloth mulching and black mulching treatments had the highest sugar-acid ratio, which were 23.81 and 24.41 , respectively. Followed by straw mulch and river sand mulch, which were 20.43 and 19.35, respectively. The CK had the lowest sugar-acid ratio (17.19), which was significantly lower than the other treatments. Black mulching and horticultural cloth mulching treatments had the highest solid-acid ratio content, which were 29.70 and 28.60 , respectively, and there was no significant difference between them. The second highest ratio was straw mulching treatment (22.47), and the river sand mulching treatment had the lowest solid-acid ratio (20.43) and lower than CK (20.68). 
Table 4. Nutritional quality after applying chelated iron to roots under different mulching materials.

\begin{tabular}{|c|c|c|c|c|c|c|c|}
\hline Treatment & $\begin{array}{c}\text { Sucrose } \\
/ \mathrm{g} \cdot 100 \mathrm{~mL}^{-1}\end{array}$ & $\begin{array}{c}\text { Sugar } \\
/ \mathrm{g} \cdot 100 \mathrm{~mL}^{-1}\end{array}$ & $\begin{array}{c}\text { Vitamin C } \\
/ \mathrm{g} \cdot 100 \mathrm{~mL}^{-1}\end{array}$ & $\begin{array}{c}\text { TSS } \\
/ \%\end{array}$ & $\begin{array}{c}\text { Titratable } \\
\mathrm{acid} / \%\end{array}$ & $\begin{array}{c}\text { Acid-sugar } \\
\text { ratio }\end{array}$ & $\begin{array}{c}\text { Solid-acid } \\
\text { ratio }\end{array}$ \\
\hline $\mathrm{A}$ & $4.15 \pm 0.009 \mathrm{~d}$ & $9.42 \pm 0.015 \mathrm{~d}$ & $10.31 \pm 0.015 \mathrm{~d}$ & $11.46 \pm 0.015 \mathrm{c}$ & $0.49 \pm 0.012 \mathrm{c}$ & $24.41 \pm 0.781 \mathrm{a}$ & $29.70 \pm 0.938 \mathrm{a}$ \\
\hline $\mathrm{B}$ & $5.08 \pm 0.007 \mathrm{~b}$ & $11.30 \pm 0.043 \mathrm{~b}$ & $11.38 \pm 0.021 \mathrm{c}$ & $12.43 \pm 0.023 \mathrm{~b}$ & $0.55 \pm 0.007 \mathrm{~b}$ & $20.43 \pm 0.188 \mathrm{~b}$ & $22.47 \pm 0.308 \mathrm{~b}$ \\
\hline $\mathrm{C}$ & $4.64 \pm 0.014 \mathrm{c}$ & $10.31 \pm 0.014 \mathrm{c}$ & $11.88 \pm 0.045 \mathrm{~b}$ & $12.39 \pm 0.019 \mathrm{~b}$ & $0.52 \pm 0.033 \mathrm{c}$ & $23.81 \pm 0.209 \mathrm{a}$ & $28.60 \pm 0.177 \mathrm{a}$ \\
\hline $\mathrm{D}$ & $6.93 \pm 0.009 \mathrm{a}$ & $13.09 \pm 0.017 \mathrm{a}$ & $13.11 \pm 0.015 \mathrm{a}$ & $13.96 \pm 0.036 \mathrm{a}$ & $0.68 \pm 0.033 \mathrm{a}$ & $19.35 \pm 0.117 \mathrm{~b}$ & $20.43 \pm 0.051 \mathrm{c}$ \\
\hline CK & $3.81 \pm 0.009 \mathrm{e}$ & $7.97 \pm 0.021 \mathrm{e}$ & $8.98 \pm 0.026 \mathrm{e}$ & $9.58 \pm 0.033 \mathrm{~d}$ & $0.47 \pm 0.033 \mathrm{~d}$ & $17.19 \pm 0.077 \mathrm{c}$ & $20.68 \pm 0.077 \mathrm{~d}$ \\
\hline
\end{tabular}

\section{Discussion and Conclusion}

This experiment showed that the treatments of black, straw, horticultural cloth, and river sand mulching all increased the single fruit weight of Huangguogan. The river sand mulching treatment had the highest single fruit weight, and the river sand mulching also significantly improved the vertical and horizontal diameters of the fruit. Different mulching treatments had a significant impact on the nutritional quality of Huangguogan fruit. Among them, river sand mulching treatment can significantly increase the contents of TSS, Sugar, TA and vitamin C. Chen [7] showed that straw and grass mulching can increase the weight and yield of longan fruits, as well as the content of soluble sugar and Vc. Mei [8] showed that different ground mulching treatments had a significant impact on the nutritional quality of Shatangju fruits. Among them, black mulching treatment can increase the content of TSS, TA and vitamin C. Gao [9] have shown that compared with CK, mulching and growing grass could improve various fruit quality indicators, while black film, white film and horticultural cloth mulching treatments did not achieve good fruit quality. Most experiments have shown that plastic film mulch can improve the yield and quality of pears, grapes, citrus and other fruits.

In summary, treatment with different mulching materials near the rhizosphere of Huangguogan could reduce soil $\mathrm{pH}$ to a certain extent, but the effect of different mulching materials was the same. At the same time, different treatments could also improve the appearance and nutritional quality of Huangguogan fruit. In general, the effects of different mulching material treatments on fruit quality were: river sand mulch > straw mulch $>$ horticultural cloth mulch $>$ black mulch.

\section{Acknowledgments}

I would like to give my sincere gratitude to professor Zhihui Wang, with extraordinary patience and consistent encouragement, gave me great help by providing me with necessary materials, advice of great value and inspiration of new ideas. It was his suggestions that draw my attention to a number of deficiencies and made many things clearer. Without his strong support, this thesis could not be the present form. My heartfelt thanks also to the people who have offered me valuable help.

\section{References}

1. M.K., Biswas, L., Chai, M.H., Amar, X.L., Zhang, X.X., Deng. (2011) Comparative analysis of genetic diversity in Citrus germplasm collection using AFLP, SSAP, SAMPL and SSR markers. Scientia Horticulturae., 129(4):798-803.

2. B., Xiong, S., Ye, Q., X, L., Liao, G.C., Sun, J.Y., Lou, L., Dai, Y., Rong, Z.H., Wang. (2017) Transcriptome Analyses of Two Citrus Cultivars (Shiranuhi and Huangguogan) in Seedling Etiolation. Scientific Reports., 7:46245.

3. J., Huang, N., Zhang, Z.P., Min. (2010) Study on the effects of different ground mulching materials on the fruit quality of early-maturing wenzhou mandarin orange and the soil temperature and water in the orange garden. South China Fruit Tree., 39(3):1517.

4. J.B., Yang, W.T., Li, J., Zhang, J.A., Ji, L., Deng, S.L., He, S.L., Yi, W.X., Zhu. (2018) The effect of plastic mulching on the fruit quality of Tarocco blood orange in orchards in Chongqing Three Gorges Reservoir Area. South China Fruit Tree., 47(1):32-34.

5. R., Chen, Y.Y., Huang, X.L., Ji, Y.H., Xu, X.M., Xue, J.Z., Wang. (2018) Effects of different mulching materials on soil, leaf and fruit quality in Yanfu 10 orchard. Tianjin Agricultural Sciences., 24(2):45-47+75.

6. Z.P., Ye. (2010) Research progress on models of photosynthesis response to light and $\mathrm{CO}_{2}$. Chinese Journal of Plant Ecology., 34(6): 727-740.

7. J.H., Chen, S.L., Ye. (2011) Research on application of mulching technology in high yield of longan. Chinese High-Tech Enterprises., 21:33-35.

8. Z.M., Mei, S.K., He, S.N., Zhang, S.H., Qu, Y.L., Tang. (2019) Effects of different ground covers on soil physical and chemical properties and fruit quality of shatang orange orchard. South China Fruit Tree., 48(3):41-43+46.

9. N., Gao. (2020) Effects of different ground covers on apple tree growth and fruit quality in the old course of the yellow river. Shandong Agricultural University. 